традиционный учебный процесс по причине значительного усложнения педагогической деятельности. Поэтому чаще всего использование в учебном процессе информационных технологий обучения ограничивается чтением лекций, подготовленных в виде презентаций PowerPoint в аудиториях, оснащенных компьютером и проектором, и проведением итогового контроля в компьютерной форме.

Кроме этого, низкий процент использования компьютерных технологий обучения в вузе во многом связан с отсутствием соответствующих программных средств и методик по их использованию. Один из способов решения этой проблемы создание мультимедийных курсов по различным разделам математики и обучение преподавателей проектированию и внедрению в учебный процесс современных средств и методов обучения, чтобы любой преподаватель мог самостоятельно и эффективно совершенствовать свою учебно-педагогическую деятельность.

Новые информационные технологии обучения ускоряют адаптацию педагога в условиях информатизации образования с формированием оптимальной для каждого конкретного преподавателя системы приемов, методов и средств управления учебнопознавательной деятельностью студентов с учетом профессионального опыта преподавателя, его индивидуально-психологических особенностей и сформировавшегося стиля преподавания.

Учебный процесс постоянно должен быть ориентирован на внедрение новых образовательных технологий. Обладая определенной гибкостью, дающей возможность варьировать цели, средства, методы обучения, информационные образовательные технологии работают на формирование устойчивого познавательного интереса к изучаемым дисциплинам.

Таким образом, существуют разные типы и виды технических средств обучения, методов и методик преподавания, новых информационных технологий, предоставляющие огромные возможности совершенствования организации учебного процесса, содержания, форм и методов обучения в вузе.

$$
* * *
$$

1. Жангисина Г.Д. Педагогика для технических вузов. - Алматы: АТУ, 2006.

2. Кулекеев Ж.А. и др. Системы менеджмента качества организаций высшего и профессионального образования. - Караганда: КарГТУ, 2004.

3. Основы открытого образования. Под ред. В.И. Солдаткина. - М.: НИИЦ РАО, 2002.

4. Смирнов С.А. Педагогика: педагогические теории, системы, технологии. - М., 1999.

5. Шакаримова А.Б., Криулько Н.С., Хегай О.М. Дистанционное обучение (опыт реализации в ВКГТУ) / Под общей редакцией д.т.н., профессора Мутанова Г.М.- Усть-Каменогорск: ВКГТУ, 2006.

Гацаева P.C-A.

\title{
Социально - культурная характеристика моноэтнического региона на примере Чеченской республики
}

Чеченский государственный университет (Россия, Грозньй)

doi: $10.18411 / \mathrm{lj}-06-2021-165$

\section{Аннотация}

В статье выявляются социально - педагогические проблемы воспитания современной молодежи. Социально - педагогические проблемы воспитания современной молодежи, обосновываются и предлагаются решения обозначенных проблем формирования духовно целостной личности.

Ключевые слова: межэтническая культура, толерантность, этническая культура, этническая идентичность, макросреда, микросреда, личность, социум. 


\section{Abstract}

The article reveals social and pedagogical problems of education of modern youth. Socio-pedagogical problems of education of modern youth, substantiate and offer solutions to the identified problems of the formation of a spiritually integral personality.

Keywords: interethnic culture, tolerance, ethnic culture, ethnic identity, macroenvironment, microenvironment, personality, society.

Чеченский этнос является титульной нацией в Чеченской республике. В разные времена, по разному называлась земля наших предков. Но эти названия были, так или иначе, связаны с народом, его населявшим. Родную землю издревле чеченцы называют обобщающим словом: «Даймохк». Что означает Земля отцов. Термин не требует особого объяснения и говорит сам за себя. Еще мы называем свою родину «Нохчийчоь». В переводе - земля чеченцев. Эти подтверждают версию о том, что с незапамятных времен, исторически определившаяся территория чеченцев, была моноэтической и принадлежала нашим предкам чеченцам. Культура и история чеченцев (самоназвание нохчий) является частью культуры кавказской и российской. Многовековая, сложная история чеченского народа -это история созидания и творчества, разносторонних связей с другими народами. Наши предки выходили за рамки внутриэтнических связей и поддерживали тесные, доброжелательные отношения с соседними регионами и народами, их заселявшими. Не смотря на малочисленность, чеченский народ сумел не раствориться и сохраниться как самостоятельный моноэтический этнос, сохраняя свою самобытную культуру и свойственные только ей, традиции. На протяжении своей многовековой истории, чеченский народ создал уникальные материальные и духовные культурные ценности: башенный комплекс, героический эпос «Илли», богатый фольклор, историческое, литературное и этнографическое наследие, нравственно - этический кодекс, своеобразное искусство.

Примечательно, что содержание всего нравственно - этического кодекса поведения чеченца, ни в какой из граф и в целом, по содержанию, не расходятся с общечеловеческими ценностями в целом. Независимо от этнической, расовой или конфессиональной принадлежности. Как нам известно, общечеловеческие ценности универсальны. Таковыми, универсальными, являются и истинно чеченские ценности. Также, и все чеченское общество было в высшей степени демократическим, без сословий и классов. В человеке, прежде всего, ценились его добродетель, доблесть и честь. Не исчерпал свои потенциальные возможности широко практикующийся ранее институт куначества (институт межэтнического сотрудничества и дружбы чеченского народа с другими народами), укрепляющий социальные и культурные связи между народами. Чеченский народ через века пронес свои этнокультурные особенности, язык, обычаи, традиции, духовно - нравственные ценности.

Идентификационные характеристики чеченского этноса - это гостеприимство, почитание старших, честность, доброжелательность, терпимость, интернационализм, преданность своей исторической родине.

Человек, его приверженность национальным духовным ценностям, нормам и принципам народной этики всегда были в центре внимания у чеченцев. И надо сказать, что одним из благородных источников изучения того, как чеченцы понимали идеал человека, является их устное народное творчество. Начать, хотя бы, с представления требований к внешности человека. Идеалом мужской внешности является высокий рост ( лекха дег1),широкие плечи (шуьйра белаш), широкая грудь ( шуьйра некха ваз ), тонкая талия (юткъа г1одаюкъ), худощавость (векъна), аккуратные, небольшие стопы и тонкие, прямые, высокие ноги, белый цвет кожи, прямой нос, широкие брови, прямые, не крупные зубы, маленький рот и уши, полная белая шея, прямая быстрая походка ( «цуьнан боларе хьаьжч хаьа и мух ву!» («по походке можно узнать, каков он») - 
говорят чеченцы. Вся одежда чеченца должно была быть пригнана к телу, ремень же затягивался туго, чтобы нельзя было протиснуть пальцы.

К признакам уже внешней женской красоты чеченцы относили средний рост, стройность, белую тонкую шею, среднюю грудь, тонкую талию (чтобы под лежащей на боку девушкой можно было просунуть кулак) маленькие ножки, изящные руки, густые ресницы, большие черные глаза, утиная плавная походка. П.К. Услар - первый исследователь чеченского народа - был удивлён сравнением походки чеченской девушки с утиной. Но чеченцы понимают под этим плавные, грациозные движения. В песнях чеченцев нередко можно встретить и такой атрибут внешности женщины, как длинные черные косы. Но, пожалуй, превыше всего чеченцы ценили соблюдение девушками своей девичьей чести, а также, верность и преданность мужу. Она считала своим первейшим долгом - свято оберегать имя и честь мужа, сыновей всей мужской половины своего рода. И это не было сверхъестественным явлением, это было обыденным явлением, поведенческой нормой повседневной бытовой жизни. Огромным достоинством женщины считалось трудолюбие, «Женщины, - пишет А. П. Берже, трудолюбивы: на них лежат хозяйственные заботы. На них же лежат хозяйственные заботы. Они же ткут сукна для домашнего обихода, делают ковры, войлоки, бурки, всю одежду для семьи. О высоком статусе женщины в чеченском обществе говорит сам термин, которым чеченцы называют замужнюю женщину: ц1ийна - нана. Что в переводе - хозяйка дома. Участи людей, не имеющих представление о культуре и традициях чеченцев, бытует мнение, что женщина - чеченка подавлена, порабощена. Сам народ этим термином определяет роль и место женщины в чеченском обществе. Она почитаема, она полноправная хозяйка своего дома. Ведет хозяйство и воспитывает детей быть благородными и достойными членами общества, соблюдая традиции и культуру народа. Серьезные требования предъявлялись к человеку, в частности, мужчине во всех сферах его жизни и деятельности. Так, весьма ценились немногословность (« Хабаршца до буьзна бац» - « Разговорами сапетку не заполнишь»). «Шина балдал арадаллалц лай ду дош ,арадели - хьо цуьнан лай ву» «Пока слово не слетит с уст ,оно подвластно человеку ,вылетело -ты его раб», несуетливость. («Сиха дахан хи х1урдах ца кхетта») - « Быстрая река до моря не дошла»),сдержанность в оценке достоинств своих детей , жены .(« Нанас хастийна йо1 мехала ца йаьлла ») - («Похвала матери обесценивает дочь»).и т.д. Особенно корректно вел себя мужчина в доме. За трапезу садился один; с женой при людях вел себя сдержанно; не брал при посторонних ребенка на руки, даже - в присутствии матери.

Отдельные поступки, действия, наиболее полно отражающие требования народной этики, передавались из поколения в поколение, становились легендой. Вот один из примеров. В период Кавказской войны был у Шамиля в селе верный и опытный мюрид - наиб Талхик. После каждой битвы с царскими войсками обходил он все похороны сельчан, выражая соболезнование своим воинам -односельчанам , но у самого у него, говорят, долго не было сына. И вот к 40 годам у него родился сын, который в 15 лет стал участвовать в войне. В одной из стычек он был убит. На следующие утро Талхик объявляет похороны (тезет) и говорит обращаюсь к жене: «Жена, 20 лет я ходил к своим односельчанам на похороны и их детей, не имея от себя ни одного бойца, сегодня же я, потерявший сына, как многие мои односельчане. И поэтому я горд, что смог за эти годы разделить с ними эту горькую участь, общее горе легче перенести, нежели личное». В Чечне возникает культ мужчины - героя «Къонах».( «Къо» - «сын»+ «народ», то есть «сын народов», «истинный мужчина»), говорят чеченцы о храбром, благородном, мужественном человеке. «Къонаха» выступает в чеченской народной поэзии борцом за правду и справедливость, проявляя храбрость и отвагу. Храбрость и бесстрашие (къонахой) ставились превыше всего, о сынах народа слагали легенды, они стали героями эпических песен чеченцев. Содержание устного народного творчества подтверждает, что у чеченцев принято судить о человеке по степени его высоких моральных качеств, а не по толщине его 
кошелька. Во все времена высоко ценили честность, благородство в отношениях с людьми, будь то противник или друг, и глубоко презирали коварство, трусость, малодушие. Будучи сами таковыми, соответствующим образом они умели ценить такое же и к себе. Замечательными чертами чеченцев, сформировавшиеся на протяжении всей истории, были также мужество, отвага. Северный Кавказ с давних времен довольно часто становился ареной столкновения интересов крупных соседних государств. И всем кавказским народам, в том числе и чеченцам, постоянно приходилось отражать могучие нашествия иноземных захватчиков. В борьбе с ними народы Кавказа всегда помогали друг другу. Сравнительно немногочисленные, чеченцы, в силу суровых исторических, природно -географических и социальных условий жизни, в дореволюционном прошлом воспитывали, подрастающее поколения в духе бесстрашия, храбрости и отваги, презрения к трусам и изменникам. С замечательной художественной силой это показал, в частности, М. Лермонтов в своей поэме «Беглец».

Сегодня задача состоит также в том, чтобы вернуть всем людям веру в такие гуманистические ценности, как социальная справедливость, уважение к человеческому достоинству, доброта, милосердие, справедливость, порядочность, другие, утраченные нами, или же, серьезно деформированные этические нормы и принципы. Чтобы воспитать молодежь в духе причастности и ответственности за состояние дел в обществе, за судьбу нашего Отечества.

Такая работа невозможна без активного и плодотворного использования наших национальных обычаев и лучших традиций всех российских народов. Любой народ, независимо от того, маленький или большой, имеет свою, сложившуюся, в процессе длительного исторического развития, материальную и духовную культуру, в которой общечеловеческие, нравственные ценности, нормы и правила поведения приобретали, в силу действия как объективных, так и субъективных факторов, национальное своеобразие и специфику.

«Истинная национальность, - писал Н. В. Гоголь, - состоит не в описании сарафана, а в самом духе народа». Действительно, одним из ярких проявлений народного духа является его обычаи и традиции. У народов Северного Кавказа, на протяжении всей многовековой истории, складывались подлинно народные, одухотворенные высокими гуманистическими идеалами обычаи и традиции. Без всестороннего изучения и знания этих обычаев, традиций трудно понять национальный характер, психологию народа. Решение такой задачи, как осуществление связи времен и преемственности в духовном развитии поколений, нравственного прогресса, невозможно формирование исторической памяти народа, роль и значимость которого, трудно переоценить в духовной культуре личности, нации в целом.

Человечество без исторической памяти, - это мир без будущего, толпа одиночек, не способных понять друг друга. Это сон разума, порождающий чудовищ и ведущий к гибели цивилизации. Чтобы правильно ориентироваться в настоящем, должным образом воздействовать и управлять современными духовными процессами, необходимо глубоко знать прошлое.

Как говорит известный писатель Анатолий Ананьев, «есть прошлое, настоящее и будущее, и между этими понятиями, определяющими и жизнь, существует связь, которую прерывать нельзя. Из понимания связи, преемственности поколений вырастают самые святые чувства - чувства родины, патриотизм.

$$
* * *
$$

1. Асмолов А. Г. Толерантность: различные парадигмы анализа // Толерантность в общественном сознании России. - М ., 1998

2. Бездухов В. П., Бездухов А. В. Ценностный подход к формированию гуманистической направленности студента - будущего учителя. - Самара: Изд - во СамГПУ, 2000.

3. Вульфов Б.З. Воспитание толерантности: сущность и средства наклонные линии // Внешкольник. 2002. № 6 . 